\title{
Prototipe Hydrophone untuk Komunikasi Bawah Air
}

\author{
RUSTAMAJI, KANIA SAWITRI, NUR WAHYU HIDAYAT \\ Teknik Elektro Institut Teknologi Nasional Bandung \\ Email : rustamajisaja@gmail.com
}

Received 28 September 2017 | Revised 21 Oktober 2017 | Accepted 22 Oktober 2017

\begin{abstract}
ABSTRAK
Dalam pencarian suatu obyek di bawah air dibutuhkan metode khusus yang digunakan dengan suara (gelombang akustik), dikarenakan suara dapat merambat dalam jarak jauh pada air. Frekuensi yang dapat diterima oleh SONAR bergantung pada alat penerima yang mengubah suara menjadi sinyal elektrik agar dapat mendeteksi frekuensi, alat penerima ini dinamakan hydrophone. Dalam penelitian ini dibuat perancangan prototipe hydrophone, yang tersusun dari transducer (akustik-elektrik) dan penguat. Berdasarkan perancangan yang telah dibuat prototipe hydrophone mampu menerima (menangkap) gelombang akustik pada range frekuensi $100 \mathrm{~Hz}-60 \mathrm{kHz}$, dengan menggunakan transducer berupa condenser microphone yang diselimuti oleh bahan karet tipis. Prototipe hydrophone tanpa pelindung anti air, dengan pelindung anti air, dan di dalam air dapat menerima (menangkap) gelombang akustik.
\end{abstract}

Kata Kunci : SONAR, hydrophone, transducer

\begin{abstract}
In finding an object beneath the water there has to be a specific method used sound (accoustic wave) in keeping with it can apread in long distance in the depth of water. The frequency which can be detected by sonar system, counts on the receiver which converts sound to electric signal so that the frequency can be detected and it is called hydrophone. In this research, there is hydrophone prototype which piled up by tranducer and amplifier. Based on the trial, hydrophone prototype can detect accoustic wave in range $100 \mathrm{~Hz}-60 \mathrm{kHz}$ with the condensor microphone as a transducer covered of thin rubber material. Besides, hydrophone prototype with or without water resistor is still capable to detect acoustic wave.
\end{abstract}

Keywords: SONAR, hydrophone, transducer 


\section{PENDAhUlUAN}

\section{$1.1 \quad$ Latar Belakang}

Dalam pencarian suatu obyek di bawah air dibutuhkan metode khusus, metode yang digunakan adalah dengan suara (gelombang akustik) dikarenakan suara dapat merambat dalam jarak jauh pada air. Suara dapat diterima dengan sistem Sound Navigation and Ranging (SONAR). SONAR terdiri dari sistem pemancar (transmitter) dan penerima (receiver) (Ismail, 2012).

Obyek di bawah air dapat mengeluarkan suara dan dapat dideteksi dengan cara mengukur frekuensi gelombang akustik yang diterima oleh SONAR (Winder, 1975). Frekuensi gelombang akustik yang dapat diterima oleh SONAR bergantung pada alat penerima yang akan mengubah suara menjadi sinyal elektrik, alat penerima ini dinamakan hydrophone (Rustamaji, 2015). Oleh karena itu, sesuai dengan latar belakang, tujuan penelitian ini adalah untuk merancang prototipe hydrophone sebagai penerima gelombang akustik pada frekuensi $100 \mathrm{~Hz}-60 \mathrm{kHz}$.

\subsection{Pengertian Sound and Navigation Ranging (SONAR)}

Sound and Navigation Ranging (SONAR) adalah sebuah tipe teknologi propagasi suara yang digunakan dan dikaji khusus bagi kepentingan militer, hampir seluruh dunia menggunakan SONAR untuk keperluan navigasi, komunikasi dan menentukan obyek di bawah air (Hansen, 2009). Frekuensi yang digunakan pada SONAR sangat bervariasi mulai dari yang sangat rendah hingga yang sangat tinggi.

Ada empat metode umum untuk mentransmisikan sinyal di bawah air yaitu melalui optik (cahaya), magnetik, listrik, dan akustik. Transmisi optik (cahaya) jarang digunakan karena air sangat buram terhadap cahaya inframerah dan ultraviolet, serta tidak terlalu transparan untuk cahaya tampak. Transmisi magnetik dapat digunakan tetapi untuk jarak yang tidak terlalu jauh. Elektromagnetik atau gelombang radio jika dilewatkan melalui air akan cepat dilemahkan oleh air, karena air adalah konduktor listrik yang baik. Oleh karena itu digunakan suara yang lebih unggul dari metode yang lain (Oslon, 1957).

Hydrophone adalah suatu alat yang dapat menangkap suara di bawah air yang dipancarkan oleh suatu obyek. Komponen utama dari hydrophone yaitu piezoelectric yang bekerja untuk menangkap suara di dalam air, kemudian suara diperkuat oleh amplifier, agar terdengar pada loudspeaker. Salah satu jenis hydrophone yang sering digunakan terbuat dari barium titanate.

\section{PERANCANGAN DAN REALISASI}

Perancangan prototipe hydrophone dibagi menjadi sensor, rangkaian amplifier, dan penggabungan dari seluruh rangkaian yang dikuatkan melalui rangkaian amplifier. Rancangan diagram blok 50rototype hydrophone seperti pada Gambar 1.

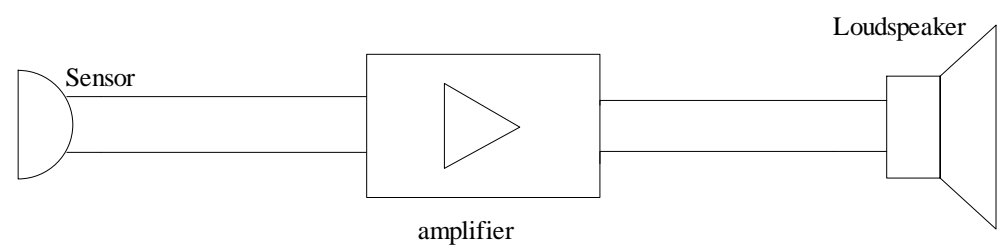

Gambar 1. Diagram Blok Prototipe Hydrophone 
Spesifikasi rancangan prototipe hydrophone yang diinginkan, yaitu :

1. Mampu mendeteksi (menerima) suara (gelombang akustik) pada frekuensi $100 \mathrm{~Hz}-60$ $\mathrm{kHz}$ di dalam air.

2. Sensor untuk mendeteksi suara (gelombang akustik) menggunakan condenser microphone.

3. Sensor tahan air menggunakan metoda selubung (diafragma) berupa karet tipis.

4. Menggunakan IC dengan kode LF356 sebagai operational amplifier.

5. Menggunakan power supply DC 9 volt dari baterai.

\subsection{Sensor}

Sensor suara yang digunakan dalam prototipe ini adalah condenser microphone, frekuensi yang dapat diterima berada dalam range $100 \mathrm{~Hz}-20 \mathrm{kHz}$ dari keterangan datasheet. Rangkaian ekivalen dari condenser microphone seperti pada Gambar 2.

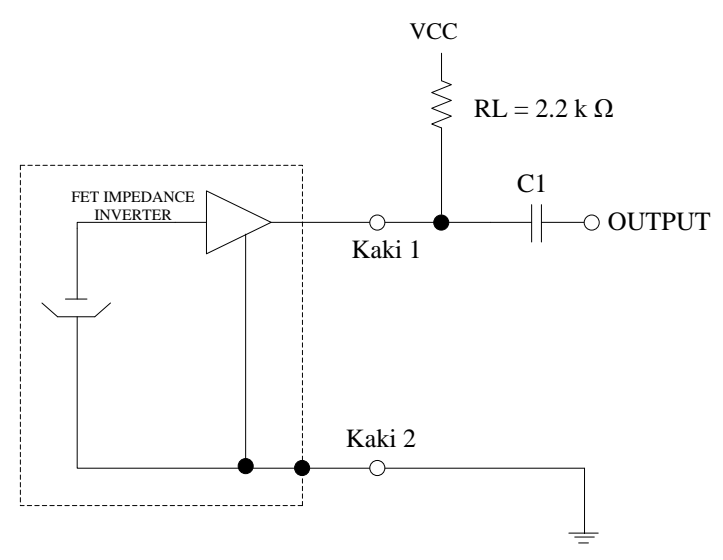

\section{Gambar 2. Rangkaian Ekivalen Condenser Microphone}

Agar condenser microphone tidak short circuit pada saat dimasukkan dalam air, dengan melindungi condenser microphone menggunakan pipa pendek dan ditutup dengan diafragma berbahan karet tipis yang kuat, rancangan seperti pada Gambar 3.

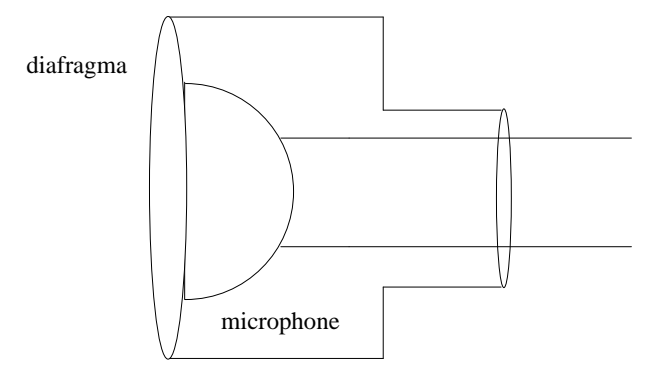

\section{Gambar 3. Rancangan Microphone Condenser Anti Air}

\subsection{Perancangan Rangkaian Penguat (Amplifier)}

Mode yang digunakan untuk rangkaian ini adalah penguat inverting. Rancangan menggunakan op-amp dengan penguatan tegangan:

$$
\frac{\mathrm{V}_{\mathrm{O}}}{\mathrm{V}_{\mathrm{I}}}=-\frac{\mathrm{R}_{4}}{\mathrm{R}_{1}}=-\frac{100 \mathrm{~K}}{1 \mathrm{~K}}=-100
$$


Beberapa komponen yang ditambahkan agar sesuai dengan penguatan yang diinginkan :

$$
\begin{aligned}
& \mathrm{V}_{1}=\mathrm{V}_{2}=\frac{1}{2} \mathrm{~V}_{\mathrm{CC}} \\
& \begin{aligned}
\frac{\mathrm{V}_{\mathrm{i}}-\mathrm{V}_{1}}{\mathrm{R}_{1}}=\frac{\mathrm{V}_{1}-\mathrm{V}_{\mathrm{O}}}{\mathrm{R}_{4}} \\
\mathrm{R}_{4}\left(\mathrm{~V}_{\mathrm{i}}-\mathrm{V}_{1}\right)=\mathrm{R}_{1}\left(\mathrm{~V}_{1}-\mathrm{V}_{\mathrm{o}}\right) \\
\mathrm{R}_{1} \times \mathrm{V}_{\mathrm{o}}=\mathrm{R}_{1} \times \mathrm{V}_{1}+\mathrm{R}_{4} \times \mathrm{V}_{1}-\mathrm{R}_{4} \times \mathrm{V}_{\mathrm{i}}=\mathrm{V}_{1}\left(\mathrm{R}_{1}+\mathrm{R}_{4}\right)-\mathrm{R}_{4} \times \mathrm{V}_{\mathrm{i}} \\
\quad \begin{aligned}
\frac{1}{2} \mathrm{~V}_{\mathrm{CC}}\left(\mathrm{R}_{1}+\mathrm{R}_{4}\right)-\mathrm{R}_{4} \times \mathrm{V}_{\mathrm{i}} \\
\mathrm{R}_{1}
\end{aligned}
\end{aligned} \\
& \begin{aligned}
\mathrm{V}_{\mathrm{o}}=\frac{\frac{1}{2} \mathrm{~V}_{\mathrm{CC}}\left(\mathrm{R}_{1}+\mathrm{R}_{4}\right)}{\mathrm{R}_{1}}-\frac{\mathrm{R}_{4}}{\mathrm{R}_{1}} \times \mathrm{Vi}
\end{aligned}
\end{aligned}
$$

Rancangan rangkaian penguat dengan op-amp seperti pada Gambar 4.

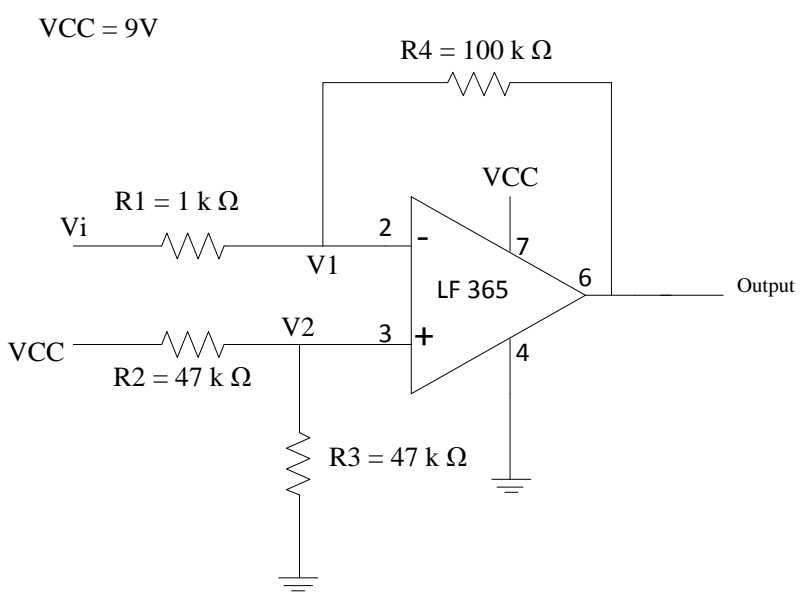

Gambar 4. Rancangan Rangkaian Penguat

Dari Persamaan 2 dengan memasukkan nilai komponen resistor $\left(\mathrm{R}_{1}, \mathrm{R}_{2}, \mathrm{R}_{3}\right.$, dan $\left.\mathrm{R}_{4}\right)$ pada Gambar 4 diperoleh besar penguatan yang dihasilkan yaitu :

$$
\mathrm{V}_{\mathrm{O}}=\left(\frac{1}{2} \mathrm{~V}_{\mathrm{cc}} \times 101\right)-\left(100 \times \mathrm{V}_{\mathrm{i}}\right)
$$

\subsection{Perancangan Rangkaian Prototipe Hydrophone}

Prototipe hydrophone yang dirancang meliputi condenser microphone dan rangkaian penguat dengan op-amp. Rangkaian prototipe hydrophone yang akan diimplementasikan seperti pada Gambar 5.

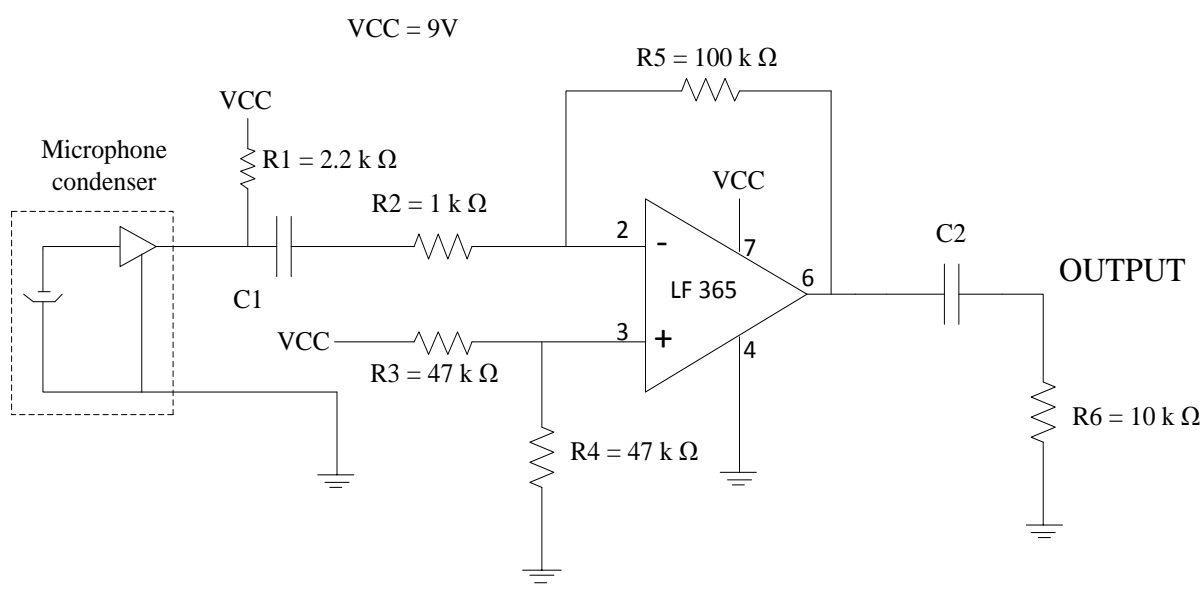

Gambar 5. Rancangan Rangkaian Prototipe Hydrophone 
Agar prototipe hydrophone dapat menerima gelombang akustik (sinyal) frekuensi rendah sebesar $100 \mathrm{~Hz}$, dilakukan perhitungan komponen penentu frekuensi yaitu kapasitor $\left(\mathrm{C}_{1}\right.$ dan $\mathrm{C}_{2}$ ). Untuk frekuensi $100 \mathrm{~Hz}$, diperoleh kapasitor kopling $\mathrm{C}_{1}$ :

$$
\begin{aligned}
\mathrm{f}_{\text {in }} & =\frac{1}{\mathrm{C}_{1} \times\left(\mathrm{R}_{1}+\mathrm{R}_{2}\right)} \\
100 & =\frac{1}{\mathrm{C}_{1} \times\left(2.2 \times 10^{3}+1 \times 10^{3}\right)} \\
\mathrm{C}_{1} & =3.125 \times 10^{-6} \mathrm{~F}
\end{aligned}
$$

Pada prototipe yang direalisasikan menggunakan kapasitor kopling $C_{2}$ sebesar $10 \mu \mathrm{F}$, maka frekuensi keluaran minimal yang dapat dilewatkan adalah :

$$
\begin{aligned}
& \mathrm{f}_{2}=\frac{1}{\mathrm{C}_{2} \times\left(\mathrm{R}_{\mathrm{L}}+\mathrm{R}_{6}\right)} \\
& \mathrm{f}_{2}=\frac{1}{10 \times 10^{-6} \times\left(2 \times 10^{3}+10 \times 10^{3}\right)}=8.3333333 \mathrm{~Hz}
\end{aligned}
$$

Supaya realisasi prototipe hydrophone pada saat dimasukkan dalam air tidak terjadi short circuit, prototipe dibungkus dengan kotak yang diberi shield berupa karet di setiap celah penutup supaya air tidak masuk, seperti pada Gambar 6.

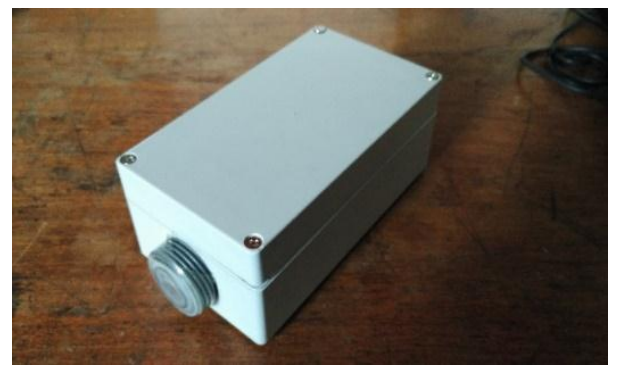

\section{Gambar 6. Realisasi Prototipe Hydrophone}

\section{PENGUKURAN DAN ANALISIS}

\subsection{Pengukuran Rangkaian Prototipe Hydrophone}

Pengukuran sinyal output akan dilakukan pada rangkaian prototipe hydrophone yang telah dirancang dan diimplementasikan, berupa amplitudo tegangan dan frekuensi sinyal yang bersumber dari audio generator yang dipancarkan oleh transmitter. Tujuan pengukuran yang diinginkan dari rangkaian prototipe hydrophone adalah mampu menangkap (menerima) suara (gelombang akustik) pada frekuensi $100 \mathrm{~Hz}-60 \mathrm{kHz}$. Diagram blok pengukuran rangkaian prototipe hydrophone seperti pada Gambar 7.

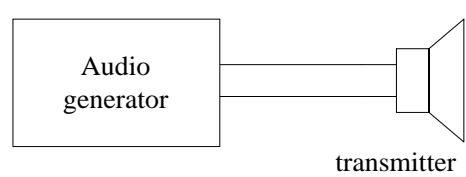

Gambar 7. Diagram Blok Pengukuran Rangkaian Prototipe Hydrophone

Dikarenakan batas maksimum frekuensi loudspeaker yang dikeluarkan adalah $20 \mathrm{kHz}$, maka untuk pengukuran $20 \mathrm{kHz}$ - $60 \mathrm{kHz}$ menggunakan transmitter yang berbeda, yakni transducer ultrasonik. Frekuensi yang dapat dikeluarkan oleh transducer ultrasonik berada dalam range $40 \mathrm{kHz}-60 \mathrm{kHz}$. 


\subsubsection{Pengukuran Tanpa Pelindung Anti Air}

Pengukuran ini dilakukan untuk mengukur amplitudo tegangan dan frekuensi sinyal yang didapatkan, apakah sesuai dengan yang diinginkan yaitu pada range $100 \mathrm{~Hz}-20 \mathrm{kHz}$. Diagram blok pengukuran rangkaian prototipe hydrophone tanpa pelindung anti air menggunakan loudspeaker sebagai transmitter, seperti pada Gambar 8.
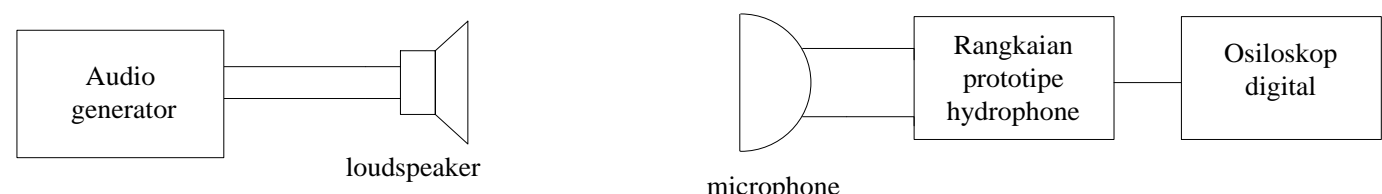

microphone

Gambar 8. Diagram Blok Pengukuran Rangkaian Prototipe Hydrophone tanpa Pelindung Anti Air dengan Loudspeaker Sebagai Transmitter

Hasil pengukuran dengan sumber sinyal sinusoida sebesar $5 \mathrm{~V}_{\mathrm{P}-\mathrm{P}}$ dari audio generator diubah-ubah frekuensinya yang dipancarkan melalui loudspeaker. Grafik dari respon frekuensi yang diukur seperti pada Gambar 9.

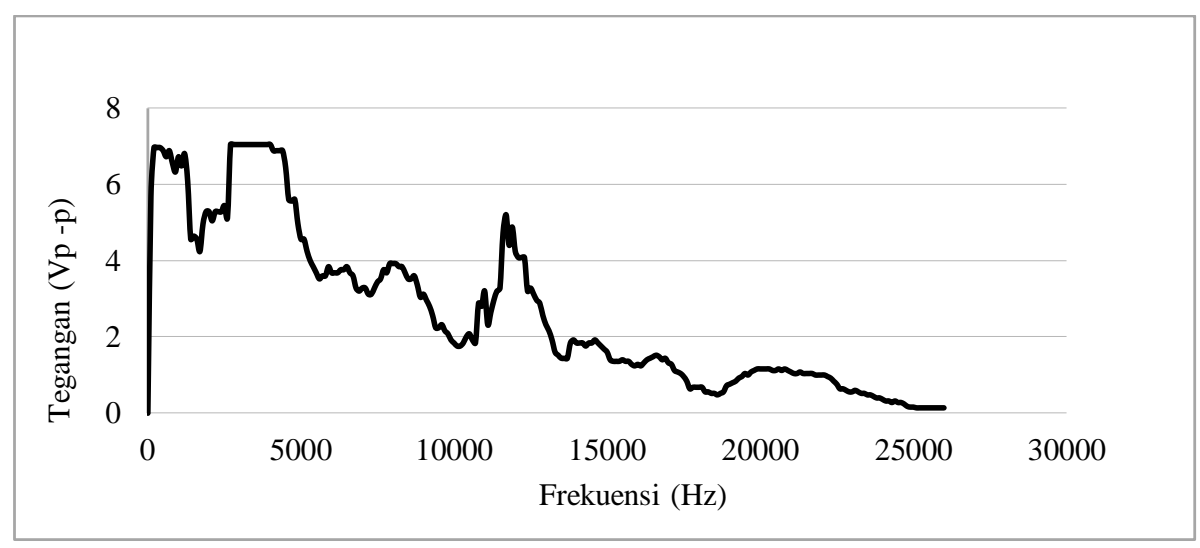

Gambar 9. Grafik Respon Rangkaian Prototipe Hydrophone pada Frekuensi $100 \mathrm{~Hz}-26$ kHz tanpa Pelindung Anti Air dengan Loudspeaker sebagai Transmitter

Pada frekuensi $4 \mathrm{kHz}$ didapat amplitudo tegangan tertinggi sebesar $7.04 \mathrm{~V}_{\mathrm{P}-\mathrm{P}}$, tetapi sinyal yang dihasilkan belum sesuai dengan sinyal pada input, hal ini dikarenakan pada perancangan rangkaian prototipe hydrophone penguatan yang dirancang adalah 100 kali, sehingga besarnya puncak tegangan terpotong, seperti pada Gambar 10.

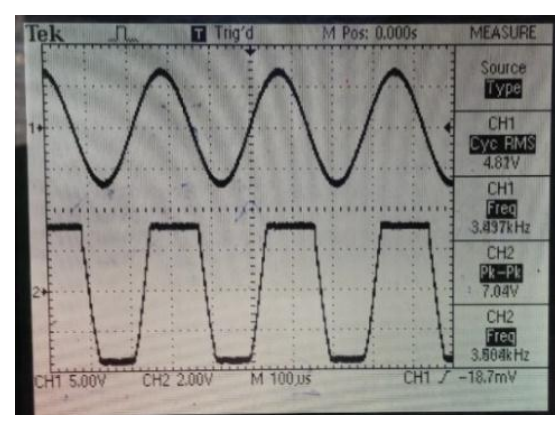

Gambar 10. Gelombang Sinyal Input dan Output Rangkaian Prototipe Hydrophone pada Frekuensi 4 kHz tanpa Pelindung Anti Air dengan Loudspeaker sebagai Transmitter 
Pada frekuensi $6 \mathrm{kHz}$, bentuk sinyal output dari rangkaian prototipe hydrophone pada ch 2 sesuai dengan bentuk sinyal input pada ch 1, seperti pada Gambar 11.

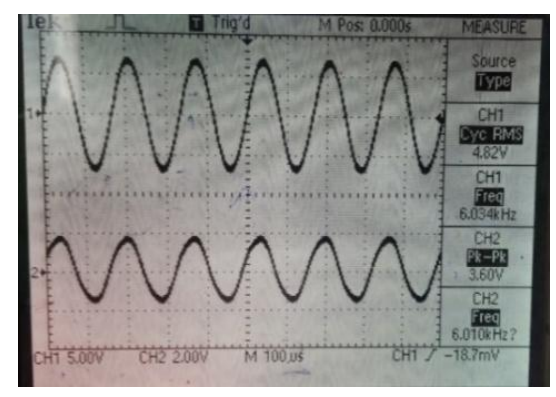

Gambar 11. Gelombang Sinyal Input dan Output Rangkaian Prototipe Hydrophone pada Frekuensi 6 kHz Tanpa Pelindung Anti Air dengan Loudspeaker Sebagai Transmitter

Diagram blok pengukuran rangkaian prototipe hydrophone tanpa pelindung anti air menggunakan transducer ultrasonik sebagai transmitter seperti pada Gambar 12.
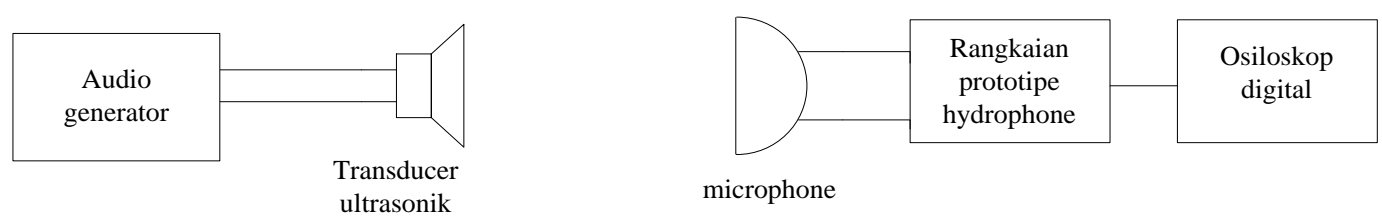

\section{Gambar 12. Diagram Blok Pengukuran Rangkaian Prototipe Hydrophone tanpa Pelindung Anti Air dengan Transducer Ultrasonik sebagai Transmitter}

Hasil pengukuran dengan sumber sinyal sinusoida sebesar $31 \mathrm{~V}_{\mathrm{P}-\mathrm{P}}$ dari audio generator diubah-ubah frekuensinya yang dipancarkan melalui transducer ultrasonik. Grafik dari respon frekuensi yang diukur seperti pada Gambar 13.

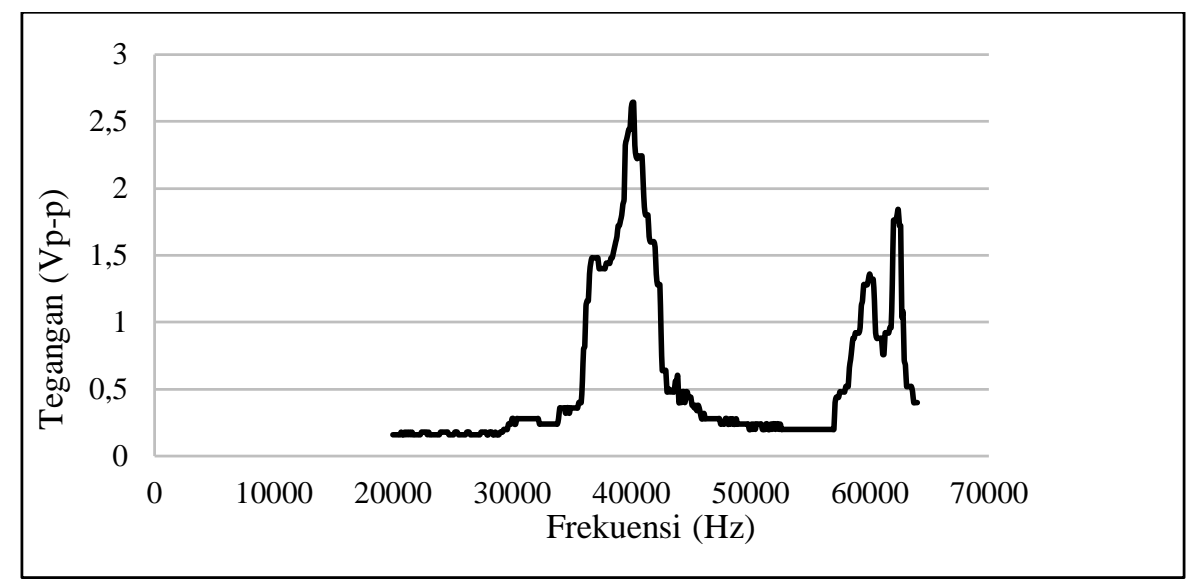

Gambar 13. Grafik Respon Rangkaian Prototipe Hydrophone pada Frekuensi 20 kHz - 64 kHz tanpa Pelindung Anti Air dengan Transducer Ultrasonik sebagai Transmitter

Pada frekuensi $36 \mathrm{kHz}-42 \mathrm{kHz}$ terjadi respon dengan amplitudo tegangan yang paling tinggi pada frekuensi $40.2 \mathrm{kHz}$ sebesar $1.2 \mathrm{~V}_{\mathrm{P}-\mathrm{P}}$, pada frekuensi $59.4 \mathrm{kHz}-62.9 \mathrm{kHz}$ terjadi respon dengan amplitudo tegangan yang paling tinggi pada frekuensi $62.4 \mathrm{kHz}$ sebesar 1.84 
$\mathrm{V}_{\mathrm{P}-\mathrm{P}}$. Gambar 14 dan 15 memperlihatkan gelombang sinyal input dan output rangkaian prototipe hydrophone.

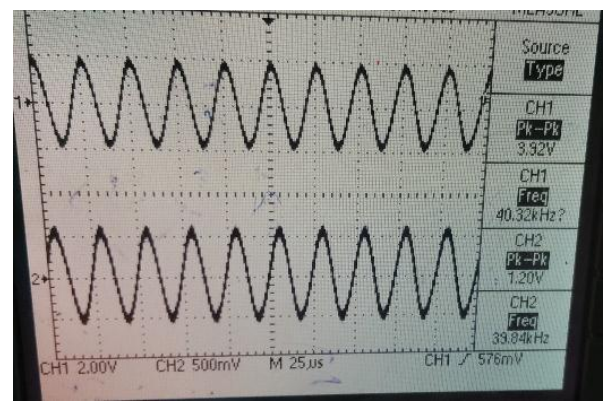

Gambar 14. Gelombang Sinyal Input dan Output Rangkaian Prototipe Hydrophone pada Frekuensi 40.2 kHz Tanpa Pelindung Anti Air dengan Transducer Ultrasonik sebagai Transmitter

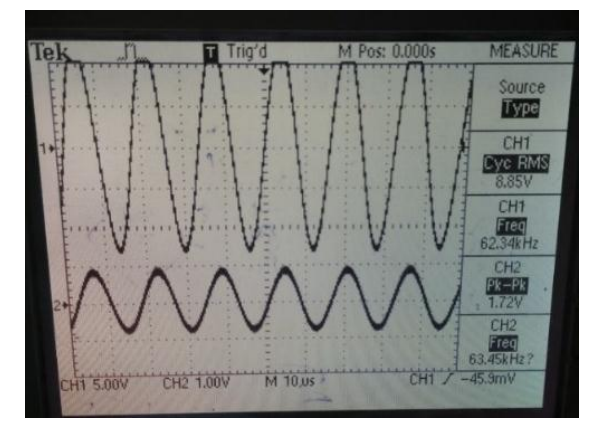

Gambar 15. Gelombang Sinyal Input dan Output Rangkaian Prototipe Hydrophone pada Frekuensi $62.4 \mathrm{kHz}$ tanpa Pelindung Anti Air dengan Transducer Ultrasonik sebagai Transmitter

Pada Gambar 14 dan 15 bentuk sinyal output dari rangkaian prototipe hydrophone pada ch 2 sesuai dengan bentuk sinyal input pada ch 1 yakni berbentuk sinusoida. Hal ini masih ditoleransi dalam cakupan range frekuensi yang diinginkan yaitu $100 \mathrm{~Hz}-60 \mathrm{kHz}$. Walaupun ada beberapa frekuensi yang tidak dapat merespon, hal ini dikarenakan keterbatasan pada transmitter yang tidak dapat memancarkan gelombang akustik pada frekuensi tertentu.

\subsubsection{Pengukuran dengan Pelindung Anti Air}

Pengukuran ini dilakukan untuk membandingkan apakah ada pengaruh dari pelindung anti air yang mempengaruhi amplitudo tegangan dan frekuensi sinyal. Diagram blok pengukuran rangkaian prototipe hydrophone dengan pelindung anti air menggunakan loudspeaker sebagai transmitter seperti pada Gambar 16.
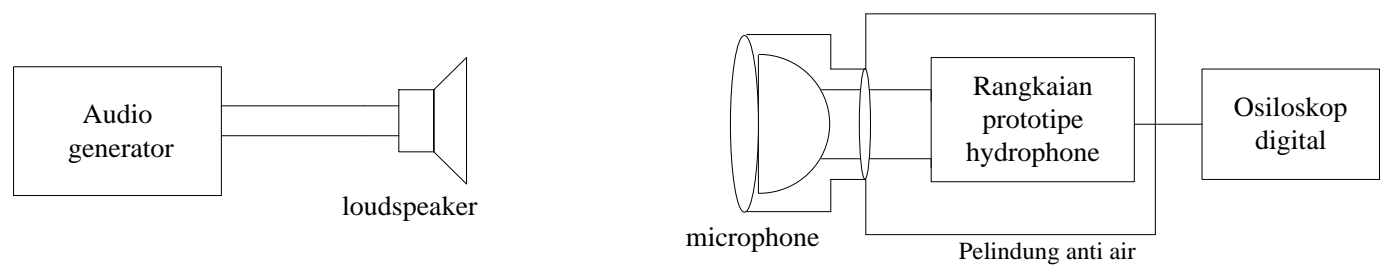

Gambar 16. Diagram Blok Pengukuran Rangkaian Prototipe Hydrophone dengan Pelindung Anti Air menggunakan Loudspeaker sebagai Transmitter 
Hasil pengukuran dimana sinyal sinusoida sebesar $5 \mathrm{~V}_{\mathrm{P}-\mathrm{P}}$ dari audio generator diubah-ubah frekuensinya yang dipancarkan melalui loudspeaker. Grafik respon frekuensi yang diukur seperti pada Gambar 17.

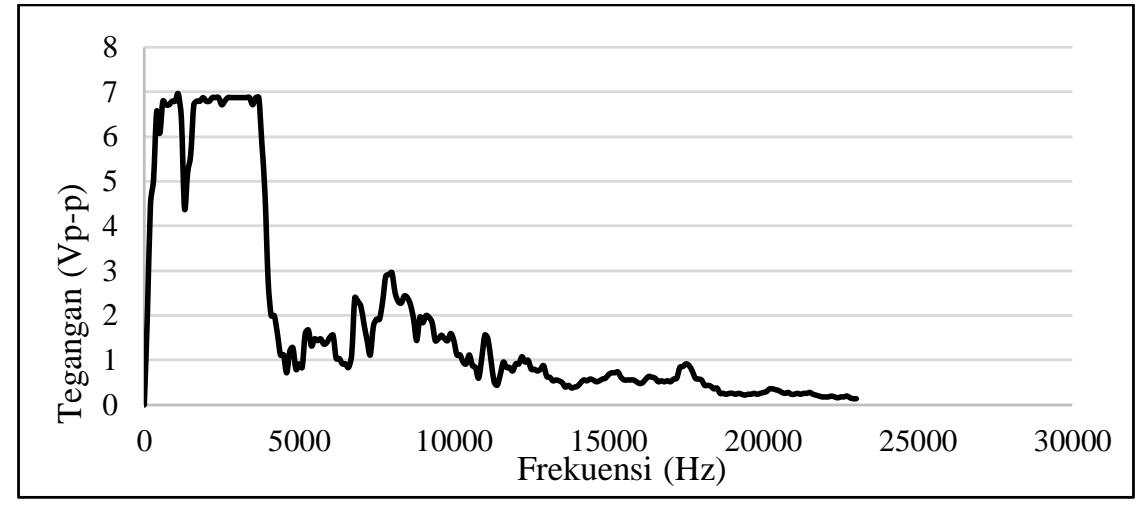

\section{Gambar 17. Grafik Respon Rangkaian Prototipe Hydrophone pada Frekuensi $100 \mathrm{~Hz}-20$} kHz dengan Pelindung Anti Air Menggunakan Loudspeaker Sebagai Transmitter

Pada frekuensi $1.1 \mathrm{kHz}$, di dapat amplitudo tegangan tertinggi sebesar $6.96 \mathrm{~V}_{\mathrm{P}-\mathrm{P}}$, tetapi bentuk sinyal ch 1 sebagai input dan ch 2 sebagai output belum sesuai, seperti pada Gambar 18.

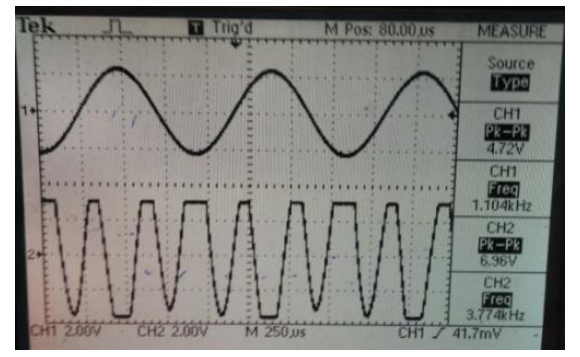

Gambar 18. Gelombang Sinyal Input dan Output Rangkaian Prototipe Hydrophone pada Frekuensi 1.1 kHz dengan Pelindung Anti Air Menggunakan LoudspeakerSebagai Transmitter

Pada frekuensi $3.8 \mathrm{kHz}$ bentuk sinyal output pada ch 2 sesuai dengan bentuk sinyal input pada ch 1 , berbentuk sinusoida dengan amplitudo tegangan sebesar $5.6 \mathrm{~V}_{\mathrm{P}-\mathrm{P}}$, seperti pada Gambar 19.

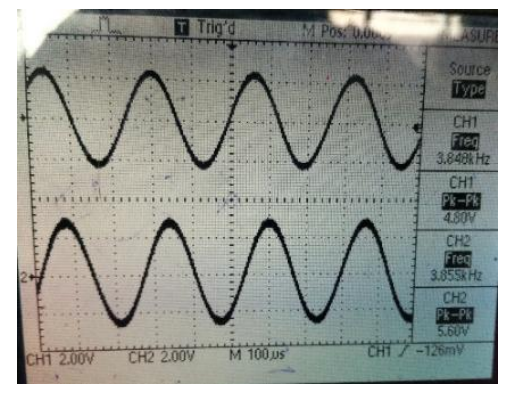

Gambar 19. Gelombang Sinyal Input dan Output Rangkaian Prototipe Hydrophone pada Frekuensi 3.8 kHz dengan Pelindung Anti Air menggunakan Loudspeakersebagai Transmitter 
Diagram blok pengukuran rangkaian prototipe hydrophone dengan pelindung anti air menggunakan transducer ultrasonik sebagai transmitter seperti pada Gambar 20.
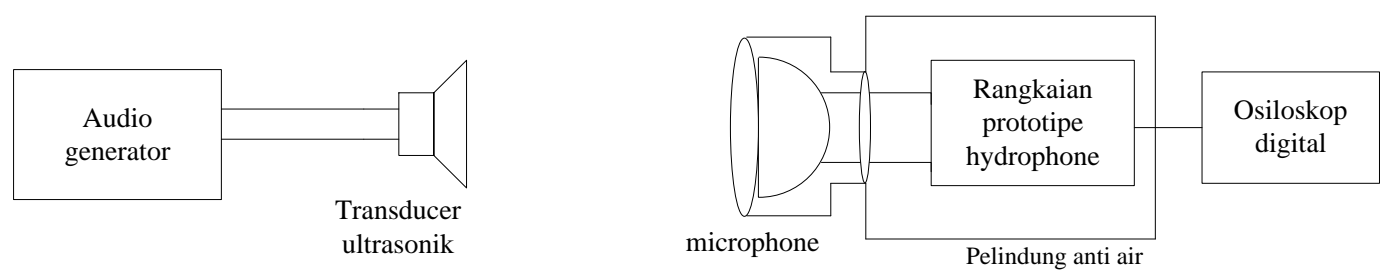

\section{Gambar 20. Diagram Blok Pengukuran Rangkaian Prototipe Hydrophone dengan Pelindung Anti Air menggunakan Transducer Ultrasonik sebagai Transmitter}

Hasil pengukuran dimana sinyal sinusoida sebesar $31 \mathrm{~V}_{\mathrm{P}-\mathrm{P}}$ dari audio generator diubah-ubah frekuensinya yang dipancarkan transducer ultrasonik. Grafik respon frekuensi yang diukur seperti pada Gambar 21.

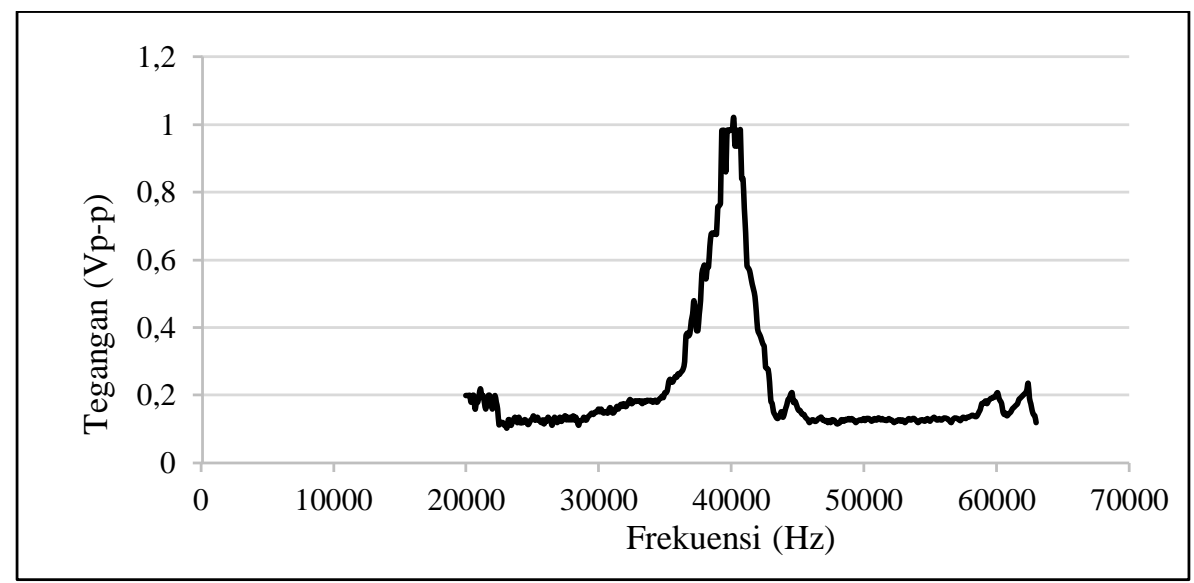

Gambar 21. Grafik Respon Rangkaian Prototipe Hydrophone pada Frekuensi 20 kHz - 63 kHz dengan Pelindung Anti Air menggunakan Transducer Ultrasonik sebagai Transmitter

Pada frekuensi $58.7 \mathrm{kHz}-62.7 \mathrm{kHz}$ dapat merespon dengan amplitudo tegangan tertinggi pada frekuensi $62.3 \mathrm{kHz}$ sebesar $0.236 \mathrm{~V}_{\mathrm{P}-\mathrm{P}}$, seperti pada Gambar 22.

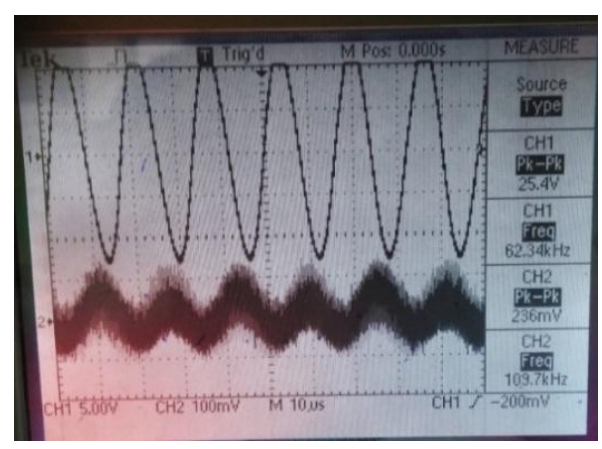

Gambar 22. Gelombang Sinyal Input dan Output Rangkaian Prototipe Hydrophone pada frekuensi 62,3 kHz dengan Pelindung Anti Air menggunakan Transducer Ultrasonik sebagai Transmitter 
Pada percobaan ini, terjadi redaman dan tidak sesuainya frekuensi pada range $58.7 \mathrm{kHz}-$ $62.7 \mathrm{kHz}$ terlihat pada ch 2 sebagai output, hal ini disebabkan oleh pelindung diafragma berbahan karet tipis yang menyelimuti condenser microphone.

\subsection{Pengujian Prototipe Hydrophone dalam Air}

Pengujian ini bertujuan untuk mengetahui prototipe hydrophone bekerja sebagaimana alat aslinya yakni mendeteksi suara (gelombang akustik) di dalam air. Diagram blok pengukuran prototipe hydrophone menggunakan garpu tala sebagai transmitter seperti pada Gambar 23.

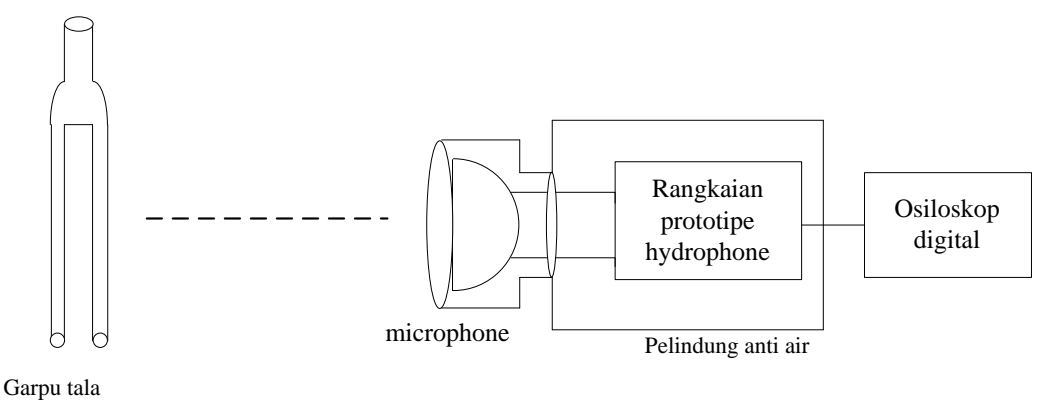

\section{Gambar 23. Diagram Blok Pengukuran Prototipe Hydrophone menggunakan Garpu Tala sebagai Transmitter}

Pengukuran ini menggunakan pembangkit getaran atau gelombang akustik (transmitter) berupa garpu tala. Pengujian yang dilakukan menggunakan 4 jenis garpu tala yang memiliki frekuensi yang berbeda. Garpu tala menghasilkan getaran berupa sinyal sinusoida dengan frekuensi sebesar $320.5 \mathrm{~Hz}$ dengan amplitudo tegangan $3.76 \mathrm{~V}_{\mathrm{P}-\mathrm{P}}$ untuk garpu tala 1, frekuensi sebesar 425.5 dengan amplitudo tegangan $1.84 \mathrm{~V}_{\mathrm{P}-\mathrm{P}}$ untuk garpu tala 2, frekuensi sebesar $441 \mathrm{~Hz}$ dengan amplitudo tegangan $1.86 \mathrm{~V}_{\mathrm{P}-\mathrm{P}}$ untuk garpu tala 3, dan frekuensi sebesar $433.8 \mathrm{~Hz}$ dengan amplitudo tegangan $0.84 \mathrm{~V}_{\mathrm{P}-\mathrm{P}}$ untuk garpu tala 4 .

Pengujian prototipe hydrophone yang dilakukan menggunakan keempat jenis garpu tala pada setiap jarak $5 \mathrm{~cm}$ dalam range $5 \mathrm{~cm}-20 \mathrm{~cm}$. Respon yang dihasilkan dari prototipe hydrophone pada setiap jarak $5 \mathrm{~cm}$ untuk garpa tala 1 dapat dilihat pada Gambar 24.

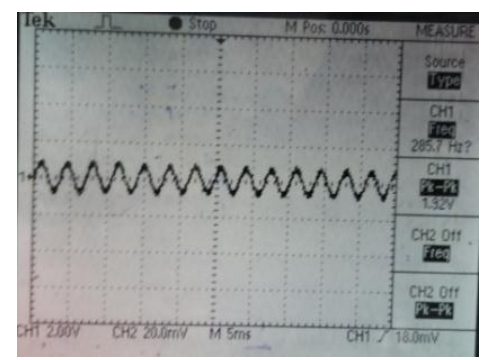

Jarak $5 \mathrm{~cm}$

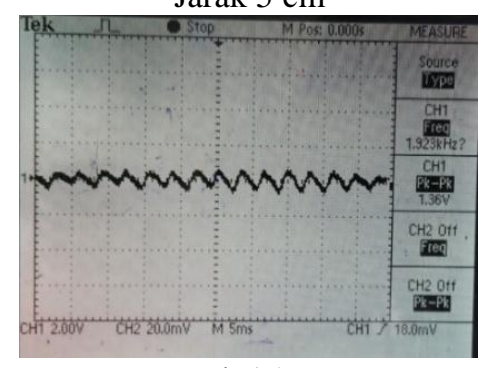

Jarak $15 \mathrm{~cm}$

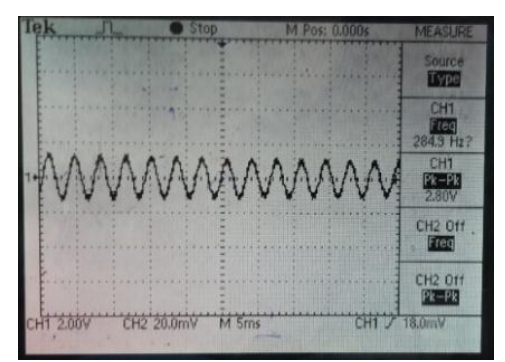

Jarak $10 \mathrm{~cm}$

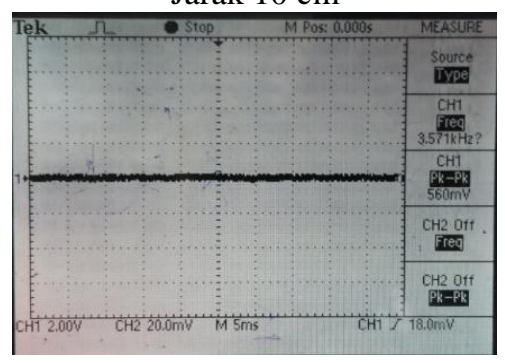

Jarak $20 \mathrm{~cm}$

Gambar 24. Gelombang sinyal yang Dihasilkan Prototipe Hydrophone dengan Garpu Tala 1 sebagai Transmitter 
Pengujian prototipe hydrophone di dalam air menggunakan keempat jenis garpu tala pada jarak $5 \mathrm{~cm}$ dan $10 \mathrm{~cm}$ prototipe masih dapat merespon. Pada saat garpu tala menjauhi prototipe hydrophone, tidak ada respon dari prototipe hydrophone, hal ini dikarenakan garpu tala tidak terus-menerus bergetar. Ketika garpu tala dimasukkan di dalam air, getaran garpu tala teredam oleh air, sehingga amplitudo tegangan dalam pengujian prototipe hydrophone dalam air berbeda dari garpu tala. Frekuensi yang diterima oleh prototipe hydrophone berbeda untuk keempat jenis garpu tala yang telah diuji, hal ini dikarenakan pada saat garpu tala dimasukan ke dalam air, getaran dari garpu tala ke segala arah permukaan bidang wadah plastik yang berisikan air.

\section{KESIMPULAN}

Setelah melakukan perancangan, merealisasikan rangkaian, mengukur dan menganalisis rangkaian perancangan prototipe hydrophone, maka diperoleh beberapa kesimpulan sebagai berikut :

1. Prototipe hydrophone yang telah dirancang mampu menangkap (menerima) gelombang akustik dalam range frekuensi $100 \mathrm{~Hz}-60 \mathrm{kHz}$ yang berasal dari transmitter berupa loudspeaker dan transducer ultrasonik, walaupun ada beberapa frekuensi yang tidak dapat merespon hal ini dikarenakan pada transmitter yang digunakan tidak dapat mengeluarkan secara konstan gelombang akustik pada range frekuensi $100 \mathrm{~Hz}-60 \mathrm{kHz}$.

2. Dengan meggunakan condenser microphone sebagai sensor, rangkaian hydrophone dapat menerima (menangkap) gelombang akustik dalam range $100 \mathrm{~Hz}-60 \mathrm{kHz}$.

3. Dengan menggunakan diafragma dari bahan karet tipis menyelimuti sensor berupa condenser microphone, rangkaian hydrophone dapat menerima gelombang akustik dalam range frekuensi $100 \mathrm{~Hz}-60 \mathrm{kHz}$.

4. Sinyal output prototipe hydrophone pada pengujian dalam air memiliki amplitudo tegangan dan frekuensi yang berbeda dengan sumber transmitter berupa garpu tala.

\section{DAFTAR RUJUKAN}

Hansen .R. E. (2009). Course Material to INF-GEO4310. University Oslo.

Ismail, S., Permana, D., Pristianto E. J. (2012). Perancangan Pemancar SONAR untuk Sistem Pendeteksi Kapal Selam. pp. 21-24.

Oslon, Harry F. (1957). Acoustical Engineering. D. Van Nostrand Company, Inc. New York.

Rustamaji, Rahmiati, P., Permatasari, S. (2015). Perancangan Prototipe Receiver Beacon Black Box Locator Acoustic 37,5 kHz Pinger. Jurnal ELKOMIKA. Bandung.

Winder, A. A. (1975). Sonar System Technology. IEEE Transactions on Sonics and Ultrasonics Vol su-22 No. 5. pp. 291-332. 